Fluorimetric Determination of 'Antrycide' DuRING trials of the new trypanocidal drug 'Antrycide' (Curd and Davey ${ }^{1}$ ) it became necessary to develop a method of determining it in plasma. This brief description of the method is published in the hope that it may be useful to other workers who use the drug.

'Antrycide' is colourless, and, although it shows blue fluorescence in ultra-violet light, a method based on this property was not sufficiently sensitive to measure the low concentrations usually found in plasma. Consequently, potential colorimetric methods were examined, particularly the general methods for organic bases that involve extraction of a coloured salt of the base into a solvent, such as those introduced by Prudhomme ${ }^{2}$ and Auerbach ${ }^{3}$, and developed mainly by Brodie ${ }^{4,5}$. Although salts of 'Antrycide' with all the thirty acid dyes examined were almost insoluble in ethylene dichloride and benzene, the solvents commonly used in procedures of this type, a technique developed by my colleague, Dr. J. Raventós $^{6}{ }^{6}$, for the colorimetric determination of $d$-tubocurarine chloride, involving extraction of an eosin salt of the alkaloid into a mixture of chloroform and butanol, was successfully applied to 'Antrycide', and found to give a highly fluorescent extract. A summary of the method follows. So far as I am aware, a fluorimetric procedure of this type has not hitherto been described.

Special reagents. (1) Stock solution of eosin (500 mgm.) in saturated sodium bicarbonate (A.R., $500 \mathrm{ml}$.). This stock solution is purified by shaking it four times with solvent mixture. (2) Buffered eosin reagent. The stock solution is diluted 1/25 with saturated sodium bicarbonate. (3) Solvent mixture. Dilute $200 \mathrm{ml}$. of re-distilled butanol to $1,000 \mathrm{ml}$. with B.P. chloroform. (4) 'Antrycide' stock standard solution, $100 \mathrm{mgm}$. $100 \mathrm{ml}$. (referred to ion). Dissolve $134.5 \mathrm{mgm}$. of dichloride dihydrate in distilled water and dilute to $100 \mathrm{ml}$. (5) 'Antrycide' working standard, $0.05 \mathrm{mgm} . / 100 \mathrm{ml}$. Dilute the stock standard when required.

Special apparatus. Coleman electronic photofluorimeter, model $12 \mathrm{~A}$.

Procedure. Dilute $1.2 \mathrm{ml}$. of plasma to $10 \mathrm{ml}$. with distilled water. Add $2 \mathrm{ml}$. of 15 per cent trichloroacetic acid, mix well and allow to stand at least 10 minutes. Centrifuge, and transfer $10 \mathrm{ml}$. of the clear upper layer to a $60-\mathrm{ml}$. glass-stoppered bottle. Add $1 \mathrm{ml}$. of $\mathrm{N}$-sodium hydroxide, $2 \mathrm{ml}$. of buffered eosin reagent and $12 \mathrm{ml}$. of solvent mixture. Shake vigorously for 3 minutes, and allow to stand until the lower layer has separated. Remove the latter, and clarify it by filtering through Whatman No. 1 or similar semi-fine paper into a Coleman fluorimeter cuvette. Read the fluorescence against a blank and standards in the Coleman fluorimeter. These are prepared by adding $0,0 \cdot 1,0 \cdot 3,0.6,1.0,2 \cdot 0$ and $3.0 \mathrm{ml}$. of the 'Antrycide' working standard to $30 \mathrm{-ml}$. bottles, treating with $2 \mathrm{ml}$. of buffered eosin reagent and $12 \mathrm{ml}$. of solvent mixture, and continuing the estimation as described above. Coleman PC 9 (pale yellow) visual filter and Coleman $B$ l (low sensitivity) or $B 1 S$ (high sensitivity) ultra-violet filter are used in the fluorimeter.

The procedure measures down to $50 \mu \mathrm{gm}$. of 'Antrycide'/litre of plasma with satisfactory accuracy ( \pm 10 per cent) and down to $20 \mu \mathrm{gm}$./litre with fair accuracy $( \pm 25$ per cent). Under carefully controlled conditions, concentrations from 5 to $20 \mu \mathrm{gm}$./1. can be detected as 'traces'. 'Antrycide' added to normal plasma is not completely recovered. The loss of about 20-25 per cent is due to precipitation of 'Antrycide' with protein, and is increased if larger volumes of plasma are used. The method has a considerable degree of specificity, since tertiary bases appear not to react under the conditions described, and many quaternary bases (for example, $d$-tubocurarine chloride, 'Dimidium' bromide and $4: 6$ diaminoquinaldinemethochloride) give only weakly fluorescing extracts. However, it is not yet possible to state that the method does not measure metabolites of the drug.

A full description of this and three other, less sensitive, methods that have been developed will be published elsewhere.

Research Laboratories,

A. SPINKS

Imperial Chemical Industries, Ltd., Hexagon House, Manchester 9.

${ }^{1}$ Curd, F. H. S., and Davey, D. G., Nature, 163, 89 (1949).

${ }^{2}$ Prudhomme, R. O., Bull. Soc. Path. exotique, 31, 929 (1938).

${ }^{3}$ Auerbach, M. E., Indust. Eng. Chem. (anal.), 15, 492 (1943).

- Brodie, B. B., and Udenfriend, S., J. Biol. Chem., 158, 705 (1945).

5 Brodie, B. B., Udenfriend, S., and Dill, W., J. Biol. Chem., 168, 335 (1947).

- Raventós, J., private communication (1948).

\section{Modified Technique for the Development of Paper Chromatograms}

IN the original publication by Consden, Gordon and Martin $^{1}$ on the application of partition chromatography on filter paper to the separation of aminoacids, the positions of these acids were determined by spraying the whole of the paper with a 01 or 0.05 per cent solution of ninhydrin in butanol. This procedure appears to have been adopted by subsequent workers in spite of inherent objections to the use of butanol in a fine spray in more or less close proximity to the operator. To avoid this objection, and to determine whether this stage could be entirely eliminated, a series of 'runs' has been made in which the ninhydrin has been incorporated in the moving phase.

Ninhydrin is readily soluble in the usual solvents such as aqueous phenol, collidine or butanol-acetic acid, and a concentration of 0.1 per cent does not appreciably affect the $R_{F}$ values of any of the aminoacids examined. The solution in phenol produces considerable intensification of colour with certain amino-acids, notably arginine and histidine, and this colour develops in a few minutes even at room temperature. The spots obtained are, however, abnormally elongated, which makes the use of phenol undesirable for this technique. With collidine or butanolacetic acid as solvent this effect does not appear, and normal spots are produced.

The technique suggested for two-dimensional chromatography is to run initially in phenol as usual, and then at right angles using a 0.1 per cent solution of ninhydrin in collidine or butanol-acetic acid. On completion of the run, the paper is warmed in a current of air to remove the solvent, and this warming is sufficient to develop the colours of the individual amino-acids. The colours are more blue than those obtained after a ninhydrin-butanol spray, and are usually of greater intensity, so that smaller quantities may be identified.

School of Medicine,

D. E. NICHOLSON

Leeds 2. Jan. 28.

${ }^{1}$ Consden, R., Gordon, A. H., and Martin, A. J. P., Biochem. J., 38, 